\title{
Deletion of the transient receptor potential cation channel TRPV4 impairs murine bladder voiding
}

\author{
Thomas Gevaert, ${ }^{1}$ Joris Vriens, ${ }^{2}$ Andrei Segal, ${ }^{2}$ Wouter Everaerts, ${ }^{1}$ Tania Roskams, ${ }^{3}$ \\ Karel Talavera, ${ }^{2}$ Grzegorz Owsianik, ${ }^{2}$ Wolfgang Liedtke, ${ }^{4}$ Dirk Daelemans, ${ }^{5}$ Ilse Dewachter, ${ }^{6}$ \\ Fred Van Leuven, ${ }^{6}$ Thomas Voets, ${ }^{2}$ Dirk De Ridder, ${ }^{1}$ and Bernd Nilius ${ }^{2}$
}

1Department of Urology, University Hospital Gasthuisberg, ${ }^{2}$ Department of Molecular Cell Biology, Division of Physiology, Laboratory of Ion Channel Research, Campus Gasthuisberg, and ${ }^{3}$ Department of Morphology and Molecular Pathology, Katholieke Universiteit Leuven, Leuven, Belgium. ${ }^{4}$ Center for Translational Neuroscience, Duke University Medical Center, Durham, North Carolina, USA. ${ }^{5}$ Rega Institute for Medical Research, Laboratory of Virology and Chemotherapy, and ${ }^{6}$ Department of Human Genetics, Experimental Genetics Group, Katholieke Universiteit Leuven, Leuven, Belgium.

\begin{abstract}
Here we provide evidence for a critical role of the transient receptor potential cation channel, subfamily $\mathrm{V}$, member 4 (TRPV4) in normal bladder function. Immunofluorescence demonstrated TRPV4 expression in mouse and rat urothelium and vascular endothelium, but not in other cell types of the bladder. Intracellular $\mathrm{Ca}^{2+}$ measurements on urothelial cells isolated from mice revealed a TRPV4-dependent response to the selective TRPV4 agonist $4 \alpha$-phorbol 12,13-didecanoate and to hypotonic cell swelling. Behavioral studies demonstrated that $T R P V 4^{-/-}$mice manifest an incontinent phenotype but show normal exploratory activity and anxietyrelated behavior. Cystometric experiments revealed that $T R P V 4^{-/-}$mice exhibit a lower frequency of voiding contractions as well as a higher frequency of nonvoiding contractions. Additionally, the amplitude of the spontaneous contractions in explanted bladder strips from TRPV4 ${ }^{-/}$mice was significantly reduced. Finally, a decreased intravesical stretch-evoked ATP release was found in isolated whole bladders from TRPV4 ${ }^{-/-}$mice. These data demonstrate a previously unrecognized role for TRPV4 in voiding behavior, raising the possibility that TRPV4 plays a critical role in urothelium-mediated transduction of intravesical mechanical pressure.
\end{abstract}

\section{Introduction}

The transient receptor potential (TRP) superfamily consists of a large number of cation channels, which can be divided into 6 subfamilies: TRPC, TRPV, TRPM, TRPP, TRPML, and TRPA. TRP channels play a general role as cellular sensors (1-3), and TRP channel malfunctioning has been linked to a growing number of human diseases (4). TRP cation channel, subfamily V, member 4 (TRPV4) is a $\mathrm{Ca}^{2+}$-permeable channel activated by a wide variety of physical and chemical stimuli (5-7).

Originally, TRPV4 was put forward as a mechano- or osmosensor, given that the channel opens in response to hypotonicityinduced cell swelling (8-11) and shear stress (12). However, TRPV4 can also be activated by diverse chemical stimuli such as the synthetic phorbol ester $4 \alpha$-phorbol 12,13-didecanoate ( $4 \alpha$-PDD) (5), the plant substance bisandrographolide A (13), endogenous endocannabinoids such as anandamide, anandamide metabolites such as arachidonic acid and epoxyeicosatrienoic acids (EETs; 5,6-EET and 8,9-EET) $(14,15)$, as well as by moderate warmth $\left(>27^{\circ} \mathrm{C}\right)$ (refs. 16, 17, and reviewed in ref. 18). Recent investigations using TRPV4 $4^{-/}$mice revealed the involvement of TRPV4 channels in sensing mechanical pressure $(19,20)$, osmolality $(20,21)$, and warmth $(22,23)$ in vivo.

Nonstandard abbreviations used: $\left[\mathrm{Ca}^{2+}\right]$, intracellular $\mathrm{Ca}^{2+} ; \mathrm{IVI}$, intervoiding interval; NVC, nonvoiding contraction; $4 \alpha$-PDD, $4 \alpha$-phorbol 12,13-didecanoate; SC, spontaneous contraction; TRP, transient receptor potential; TRPV4, TRP cation channel, subfamily V, member 4; VC, voiding contraction.

Conflict of interest: The authors have declared that no conflict of interest exists. Citation for this article: J. Clin. Invest. 117:3453-3462 (2007). doi:10.1172/JCI31766.
In the urinary bladder, the closely related TRPV1 channel is expressed in sensory nerve terminals, in the epithelial cells lining the bladder lumen (urothelium) (24), and in interstitial cells (25). Analysis of TRPV1 $1^{-/-}$mice indicated that TRPV1 participates in normal bladder function (26). Mice lacking TRPV1 display a higher frequency of low-amplitude nonvoiding bladder contractions (NVCs) in comparison with wild-type animals. TRPV1 is required for bladder stretch detection, which involves stretch-evoked release of ATP and nitric oxide. Release of both mediators is reduced in bladders excised from TRPV1 $1^{-/-}$(for a review of TRP channels in bladder dysfunction, see refs. 4, 26).

Expression of other TRP channels, e.g., TRPM8 and TRPA1, is found in sensory $C$ fibers in the bladder $(27,28)$. TRPM8 forms the basis of the diagnostic ice water test to determine whether disturbance of bladder function involves a neurogenic component (29). The presence of TRPV4 in bladder urothelium has been mentioned before (30), but was not shown in that report. However, thus far it is unknown whether TRPV4 channel contributes to bladder function. Here we show, for what we believe to be the first time, expression of TRPV4 in the urothelium of mouse and rat. Furthermore, we examined the bladder function in wild-type mice and mice in which the TRPV4 gene had been disrupted. We demonstrate that TRPV4 has an important role in normal bladder function, possibly by regulating ATP release from bladder urothelium in response to increased intravesicular pressure.

\section{Results}

TRPV4 is expressed in bladder urothelium. To investigate the expression of TRPV4 in the bladder, we first performed immunofluorescence 

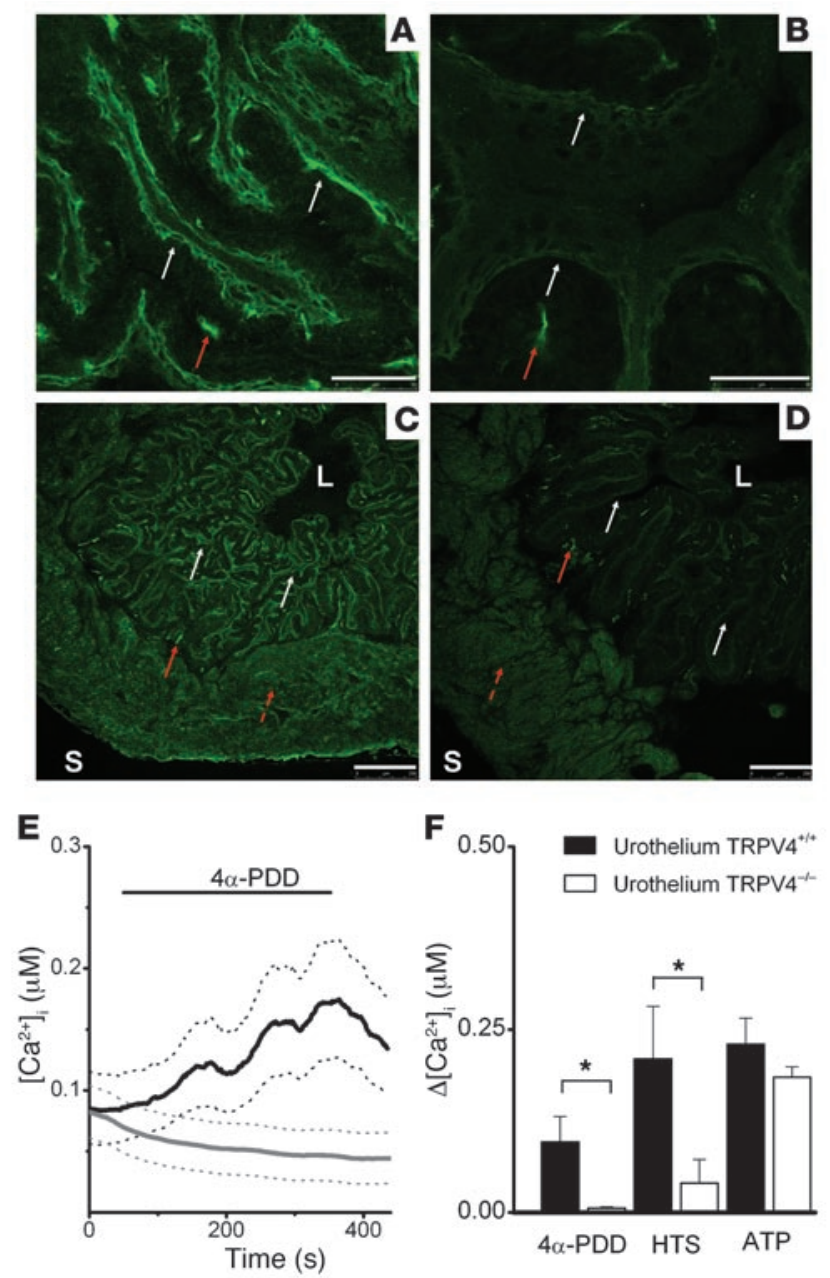

experiments with specific anti-TRPV4 antibodies (Supplemental Figure 1; supplemental material available online with this article; doi:10.1172/JCI31766DS1) on bladders from wild-type $\left(\mathrm{TRPV4}^{+/+}\right)$and TRPV4-deficient (TRPV4-/-) mice (Figure 1). Immunofluorescence showed TRPV4 mainly in urothelium (Figure 1A) and also in endothelium (data not shown). A similar urothelial staining was obtained in rat bladder (Supplemental Figure 2A). The specificity of the staining was confirmed on bladders dissected from TRPV4-/- mice, where no urothelial immunoreactivity was detected (Figure $1 \mathrm{~B})$. Some immunoreactivity was found in the suburothelium of TRPV4 $4^{+/+}$and TRPV4-/- bladders (Figure 1). Such reactivity was also observed with classic immunohistochemistry in both phenotypes (Supplemental Figure 2, C and D) and was less pronounced in rat (Supplemental Figure 2, A and B). This suburothelial immunoreactivity is then likely to be nonspecific, non-TRPV4, and partially species related. Additional fluorescent activity was seen in the detrusor region (both muscular and intermuscular) of $T R P V 4^{+/+}$and $T R P V 4^{-/-}$bladders (Figure 1, C and D). The muscular immunofluorescence seems to be non-TRPV4 related nonspecific staining of the antibody, since it was not observed with classic immunohistochemistry (Supplemental Figure 2, B and D) and was still visible after omission of the primary antibody (data not shown). The intermuscular immunoreactivity seemed to be more pronounced in TRPV4 ${ }^{+/+}$bladder both with immunofluorescence (Figure 1, C and D) and classic

\section{Figure 1}

Immunohistochemical and functional evidence for TRPV4 on urothelium. (A-D) Confocal laser scanning microphotographs of mouse bladder with staining against TRPV4 in mouse bladder. Scale bars: $50 \mu \mathrm{m}$ (A and B), $250 \mu \mathrm{m}$ (C and D). (A) Urothelium from TRPV4 ${ }^{+/+}$mouse is immunoreactive for TRPV4 (white arrows). TRPV4 immunoreactivity delineates multiple layers of urothelial cells. Notice nonspecific, nonTRPV4 immunoreactivity in the suburothelium (red arrow). (B) Urothelium from TRPV4 ${ }^{-/-}$mouse is not immunoreactive for TRPV4 (white arrows). Suburothelial nonspecific, non-TRPV4 immunoreactivity is indicated by the red arrow. (C) Full thickness slide of TRPV4+/+ bladder, delineated by luminal (L) and serosal (S) borders. Notice urothelial TRPV4 immunoreactivity (white arrows), suburothelial non-TRPV4 immunoreactivity (full red arrow), and detrusor nonspecific fluorescence (broken red arrow). (D) Full thickness slide of TRPV4 ${ }^{-/-}$bladder delineated by luminal and serosal borders. Notice absence of urothelial TRPV4 immunoreactivity (white arrows), presence of suburothelial non-TRPV4 immunoreactivity (full red arrow), and detrusor nonspecific fluorescence (broken red arrow). (E) Time course of $\left[\mathrm{Ca}^{2+}\right]_{i}$ increase caused by application of $5 \mu \mathrm{M} 4 \alpha-P D D$. Black lines indicate TRPV4+/; $n=20)$. Gray lines indicate TRPV4 ${ }^{-/}$mice $(n=20)$. Solid lines indicate mean, and dotted lines indicate SEM. (F) Average $\left[\mathrm{Ca}^{2+}\right]_{i}$ increases in urothelium isolated from TRPV4+/+ (black bars) and TRPV4 ${ }^{-{ }^{-}}$(white bars) mice in response to application of $5 \mu \mathrm{M} 4 \alpha-\mathrm{PDD}$, hypotonic solution, and $100 \mathrm{nM}$ ATP. All data represent mean \pm SEM, by unpaired Student's $t$ test. ${ }^{*} P<0.05$.

immunohistochemistry (Supplemental Figure 2, C and D), most likely because of endothelial TRPV4. However, the presence of TRPV4 on small intermuscular nerve fibres cannot be excluded.

Double staining in mouse (data not shown) and rat (Figure 2) with the intermediate filament protein cytokeratin 7 , which is present in all urothelial layers (31), showed TRPV4 to be localized on the full surface (apical and basolateral) of basal and intermediate urothelial cells, but only limited on the apical ones (umbrella cells). The apical membranes of the umbrella cells were obviously TRPV4 negative, while the basolateral membranes seem to carry at least some TRPV4 (Figure 2, A and B) $(31,32)$. No differences in microscopic structural (based on immunohistochemistry) and ultrastructural (based on electron microscopy) differences were found between bladders from both groups (data not shown). The presence of TRPV4 on mouse urothelium was further confirmed with quantitative PCR reactions on urothelial strips from $T R P V 4^{+/+}$ animals. These experiments also showed a much higher expression of TRPV4 compared with the closely related TRPV1 in urothelium. No TRPV1 upregulation was found in TRPV4-/- urothelium or vice versa. TRPV4 was decreased in TRPV1-/- urothelium, although not significantly (Supplemental Figure 3).

Next we performed intracellular $\mathrm{Ca}^{2+}\left(\left[\mathrm{Ca}^{2+}\right]_{\mathrm{i}}\right)$ measurements to evaluate functional expression of TRPV4 channels in isolated urothelium cells. The urothelial origin of these cultured cells was confirmed with positive staining for cytokeratin 7 (data not shown). We compared the response to 2 different TRPV4-activating stimuli in urothelium cells isolated from $T R P V 4^{+/+}$and TRPV4-/- mice. Stimulation with $4 \alpha$-PDD $(5 \mu \mathrm{M})$ (Figure 1E) or $25 \%$ hypotonic solution (HTS) evoked robust increases in $\left[\mathrm{Ca}^{2+}\right]_{i}$ in $\mathrm{TRPV}^{+/+}$urothelial cells. The response to $4 \alpha$-PDD was absent in $\mathrm{Ca}^{2+}$-free extracellular medium (data not shown; $n=9$ ), indicating that TRPV4 is a plasmalemmal $\mathrm{Ca}^{2+}$ entry channel in these cells. In urothelial cells isolated from TRPV4-/- mice, the response to $4 \alpha$-PDD was totally absent, whereas the response to HTS was strongly reduced but still detectable (Figure 1F), possibly by acti- 

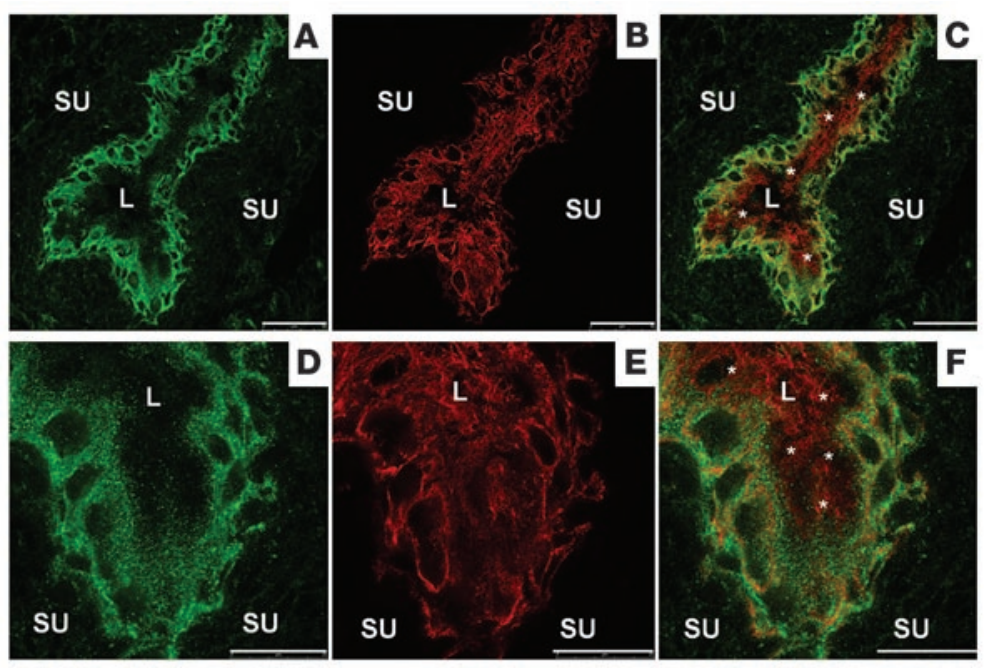

\section{Figure 2}

Regional distribution of TRPV4 throughout urothelium. Confocal laser scanning microphotographs of rat bladder showing double staining against TRPV4 (A and D), cytokeratin 7 ( $\mathbf{B}$ and $\mathbf{E})$, and mixed staining ( $\mathbf{C}$ and $\mathbf{F})$. Notice the localization of TRPV4 on basal and intermediate urothelial cell layers. The apical membranes of the umbrella cells (asterisks) appear TRPV4 negative, whereas the basolateral membranes exhibit some weak staining for TRPV4. Scale bars: $50 \mu \mathrm{m}$ (A and C), $25 \mu \mathrm{m}$ (D-F). SU, suburothelium.

between TRPV4 ${ }^{-/-}$and TRPV4 ${ }^{+/+}$mice became clear when we analyzed short-term voluntary voiding in freely moving mice placed on filter paper over a 24 -hour period (12-hour light/12-hour dark cycle). TRPV4 ${ }^{++}$animals showed a strict urine voiding pattern, with a high urine spot frequency in the corner(s) of the cage and very little or no urine spots in the middle of the cage (Figure $3 \mathrm{~A})$. The urine spot pattern of TRPV4-/- mice was much vation of other volume-sensitive $\mathrm{Ca}^{2+}$ entry or release pathways. As a control stimulus we used ATP $(100 \mathrm{nM})$, which has been shown to causes an increase in $\left[\mathrm{Ca}^{2+}\right]_{i}$ in vascular endothelial cells via activation of purinergic receptors $(14,15)$. Likewise, ATP stimulation induced $\mathrm{a} \mathrm{Ca}^{2+}$ signal in urothelial cells, and the amplitude of the ATP response was similar in cells derived from $T R P V 4^{+/+}$and TRPV4 $4^{-/-}$mice, indicating that this increase in $\left[\mathrm{Ca}^{2+}\right]_{i}$ does not depend on TRPV4.

Taken together, immunostaining, quantitative PCR, and $\left[\mathrm{Ca}^{2+}\right]_{\mathrm{i}}$ measurements demonstrate that TRPV4 is functionally expressed in urothelial cells from the mouse bladder.

TRPV4-/- mice show an abnormal urine voiding pattern. Comparison of $\mathrm{TRPV4}^{-/-}$mice with $\mathrm{TRPV4^{+/+ }}$ littermates revealed no differences in bladder weight, residual urine osmolarity, or urine $\mathrm{pH}$ (data not shown). Remarkable differences in bladder function

\section{Figure 3}

Spontaneous voiding pattern of unrestrained TRPV4 $4^{+/+}$ and TRPV4 ${ }^{-1-}$ mice. Photographs of filter papers taken out from the bottom cages containing single TRPV4 $4^{+/+}$ (A) or TRPV4-/- mice (B) for 24 hours. Under ultraviolet light, urine spots are distinguished from the blue background by their lighter or yellowish color. Arrows labeled $a, b$, and $c$ point to areas and voiding volumes of 0.22 $\mathrm{cm}^{2}(2.75 \mu \mathrm{l}), 1.6 \mathrm{~cm}^{2}(20 \mu \mathrm{l})$, and $3.4 \mathrm{~cm}^{2}(42.5 \mu \mathrm{l})$, respectively. (C and $\mathbf{D})$ Normalized probability density functions (pdf) of finding urine spots along the $x$ and $y$ axes of the cage for TRPV4+/+ (black lines) and TRPV4 ${ }^{-/-}$(red lines) mice. (E) Average total spot area expressed as percentage of the total area of the cage. (F) Mean total number of spots and mean number of spots appearing away from the cage corners (out-ofcorner). (G) Cumulative distribution functions (Cdf) for the area and volume of voiding for clearly discernible single spots (occurring away from the cage corners). The black square and the red circle indicate the mean values of the single-spot area and voiding volume for TRPV4 ${ }^{+/+}$and TRPV4 $4^{-/-}$mice, respectively. Data from $14 \mathrm{TRPV}^{+/+}$mice and $23 \mathrm{TRPV}^{-/-}$mice. All data are mean \pm SEM, by Student's $t$ test. ${ }^{*} P<0.05$.
A
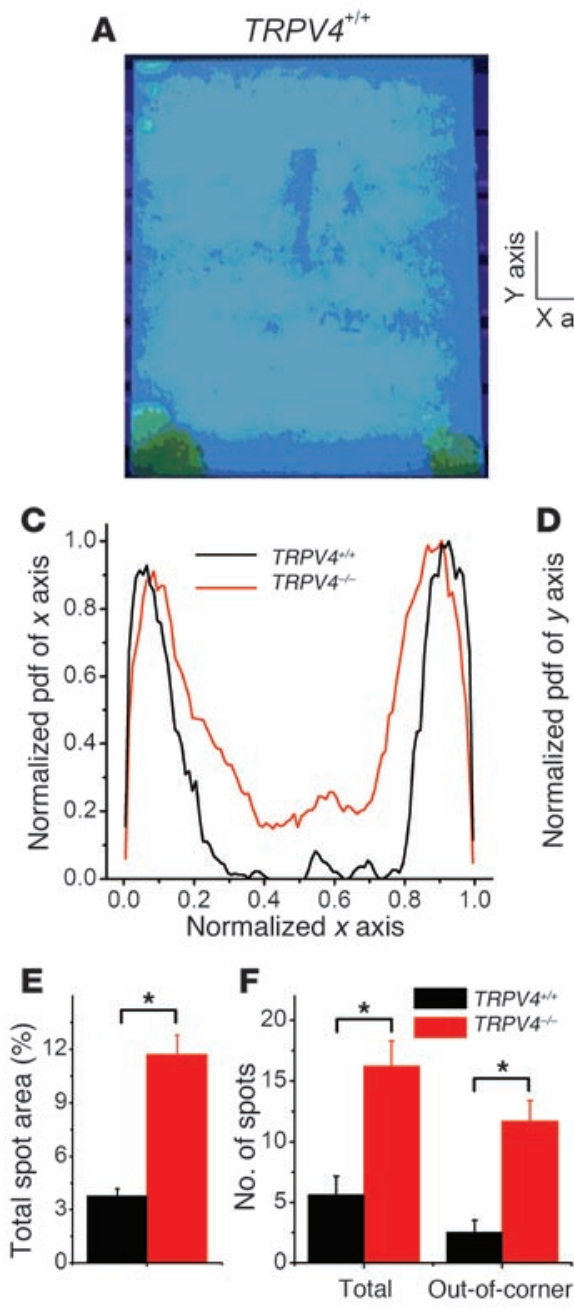

B

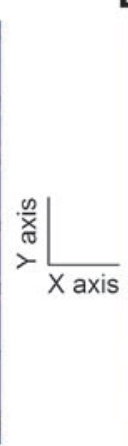

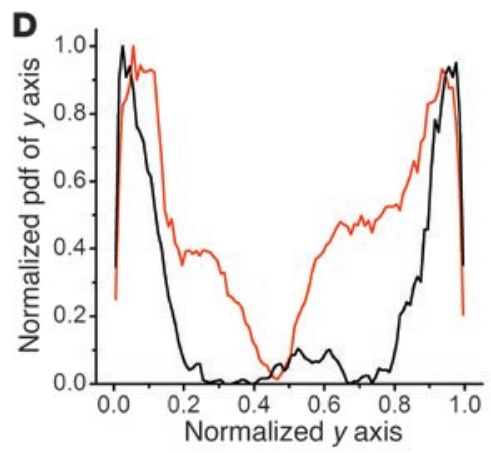

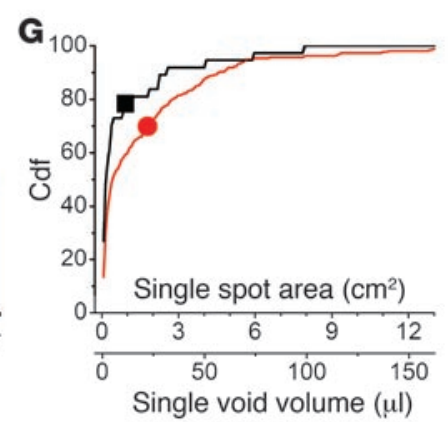



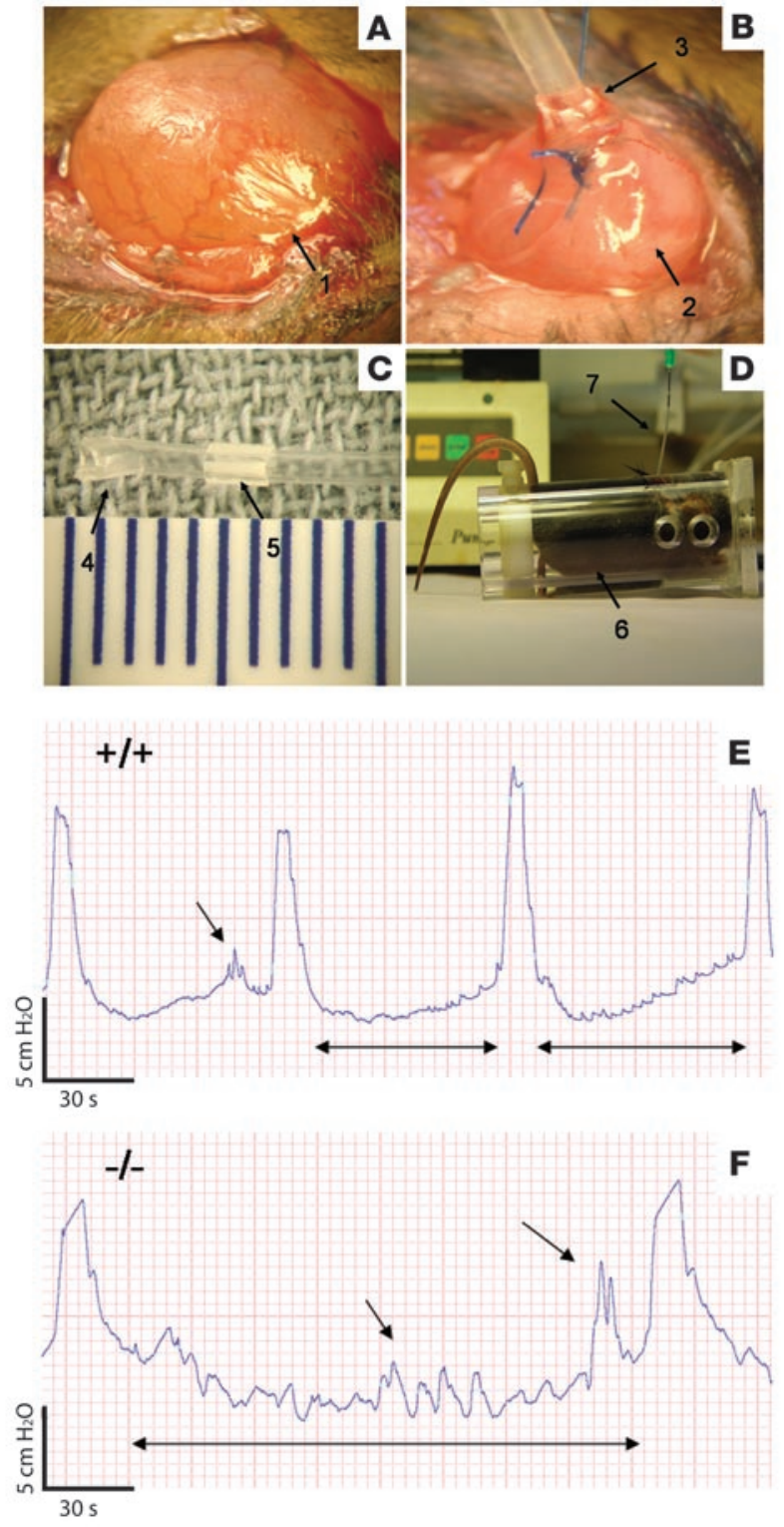

of finding urine spots along the $x$ and $y$ axes of the cage. Pooled data from TRPV4 ${ }^{+/+}(n=14)$ and TRPV4-/- $(n=23)$ mice, after normalization to their respective maximum values, are shown in Figure 3, C and D. This analysis confirmed that TRPV4+/+ mice voiding occurred almost exclusively in the corners (i.e., the left- and rightmost $20 \%$ of the $x$ and $y$ axes), whereas TRPV4-/- produced urine spots along the entire $x$ and $y$ axes. Consistent with these observations, the total spot area, the number of discernible spots, and the number of spots away from the corners were all significantly higher for the TRPV4-/- mice than for TRPV4 $4^{+/+}$littermates (Figure 3, E and F). Moreover, when analyzing the size and corresponding volume of individual urine spots located away from the corners, we found a significantly higher probability of large voidings in the TRPV4 ${ }^{-/-}$than in TRPV4 ${ }^{+/+}$mice (Figure $3 \mathrm{G}$ ). The mean area of these spots and the corresponding mean voiding volumes were $0.91 \mathrm{~cm}^{2}$ and $1.8 \mathrm{~cm}^{2}$ and $11.4 \mu \mathrm{l}$ and $22.5 \mu \mathrm{l}$ for $T R P V 4^{+/+}$ and TRPV4 ${ }^{-/-}$mice, respectively. A similarly disturbed urination pattern in the TRPV4-/- mice was observed during 12-hour peri-

\section{Figure 4}

Materials and methods for cystometry. (A) Bladder after minilaparotomy (arrow 1), (B) bladder (arrow 2) with implanted catheter (arrow 3), (C) bladder catheter with fixed (arrow 4) and movable (arrow 5) cuffs, and (D) cystometric measurement on a restrained mouse (arrow 6) undergoing constant bladder filling and intravesical pressure monitoring through an implanted catheter (arrow 7). (E and F) Original recordings of cystometric experiments. Intravesical pressure changes during intravesical infusion with iso-osmotic solution (Krebs) in TRPV4+/+ (E) and TRPV4 ${ }^{-/}$mice $(\mathbf{F})$ are presented. This set of urodynamical data shows differences in the micturition cycle in TRPV4-/- animals: a longer intermictional interval (double-headed arrows) associated with more nonmictional contractions (single-headed arrows).

ods of light as during 12-hour periods of darkness, indicating that these disturbances were not linked to the circadian rhythm (data not shown for observations in 12 different TRPV4 $4^{+/}$and TRPV4-/mice). To exclude that changes in anxiety-related behavior underlaid the altered urine spotting pattern in TRPV4-/- mice, we performed behavioral tests (open field test [ref. 33] and light/dark exploration test [ref. 34]) on TRPV4 ${ }^{+/+}$and TRPV4 $4^{-/-}$mice. These tests revealed an exploratory activity and anxiety-related behavior in TRPV4 $4^{-/-}$mice that was indistinguishable from their TRPV4 $4^{+/+}$ littermates (Supplemental Figure 4).

We further studied the urine voiding behavior by performing intravesical pressure measurements in awake mice (cystometry; for surgery procedure Figure 4, A-D). During constant bladder filling with iso-osmotic solutions $(300 \mathrm{mOsm} / \mathrm{kg})$, a changed voiding pattern in TRPV4-/- mice became apparent (Figure 4, E and F). The frequency of voids per time unit was significantly lower in TRPV4-/mice (Figure 5A), which equalled a significantly longer intervoiding interval (IVI) (Figure 5B). The variance of both the frequency of nonvoiding contractions (NVCs) and the intermictional interval was dramatically increased in the knockouts as compared with the $\mathrm{TRPV4}^{+/+}$animals (Figure 5, A and B). Moreover, during the filling phase (IVI) we found significantly more NVCs in $\mathrm{TRPV}^{-{ }^{--}}$mice (Figure 5A). No significant differences were found in amplitude or duration of both voiding contractions (VCs) and NVCs (Figure $5, \mathrm{C}$ and D). The total amount of urine per cystometric-induced voiding episode (IVI plus VCs) was greater in TRPV4-/- mice $(29 \pm 3$ $\mathrm{mg}$ for TRPV4 $4^{++}$and $106 \pm 20 \mathrm{mg}$ for TRPV4-/- mice; $\left.P<0.01\right)$.

Bladder strips from TRPV4 ${ }^{-/-}$mice show limited changes in spontaneous contractility. To test if the micturition phenotype in the TRPV4-/mice arose from an effect on reflex modulation via afferent/efferent nerves, bladders were isolated and dissected strips were prepared and subjected to an equal tension so that spontaneous contractions (SCs) could be measured. The amplitudes of contractions (transients) in bladder strips from $T R P V 4^{-/-}$mice were significantly decreased (measured under iso-osmotic conditions and with a tension of 1 gram on the muscle strips) (Figure 6, B and C) compared with $\mathrm{TRPV4}^{+/+}$(Figure 6, A and C). The duration and frequency of transients were unaffected (data not shown). The response to the nonselective muscarinic agonist carbachol $(0.1 \mu \mathrm{M})$, mainly an increase in baseline tension (Figure 6A), was conserved in TRPV4 $4^{--}$ bladders (Figure 6, B and C).

Removing the urothelium induced an obvious decrease in contractile amplitude (Figure 6D) and frequency (data not shown) in both TRPV4 ${ }^{-/-}$and TRPV4 ${ }^{+/+}$bladder strips. After removal of the urothelium, there was no longer a significant difference in contractile amplitude between the groups (Figure 6D), and in both 

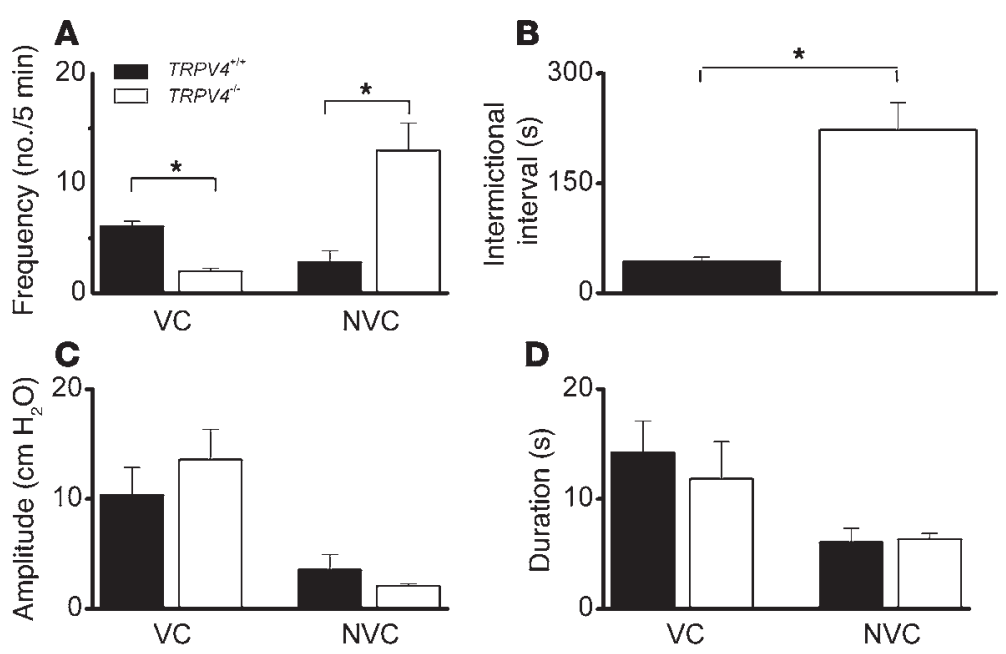

D

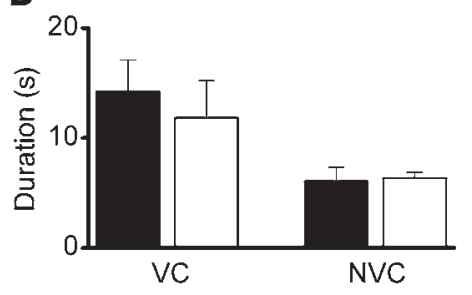

\section{Figure 5}

Behavior of several urodynamical parameters in TRPV4+/+ and TRPV4--- mice. (A) The frequency of voiding is decreased, while the frequency of NVCs is increased, in TRPV4 $4^{-/}$mice (white bars) compared with TRPV4 ${ }^{+/+}$mice (black bars). (B) Consistent with previous results, the intermictional interval is increased in TRPV4 ${ }^{-1-}$ mice. (C) No significant differences were found in the amplitude of both voiding and NVCs in TRPV4 $4^{-/-}$mice. (D) No significant differences were found in the duration of both voiding and NVCs in TRPV4-/- mice. Data from 12 animals for each group. All data are mean \pm SEM, by Mann-Whitney rank test. ${ }^{*} P<0.05$. groups the carbachol-induced increases in baseline tension was higher after removal of the urothelium (Figure 6D).

Decreased stretch-evoked intravesical ATP release in isolated whole bladders from TRPV4 ${ }^{-/-}$mice. To study a role for urothelial TRPV4 in intravesical ATP release, we compared baseline and stretch-evoked release of ATP in TRPV4 $4^{+/}$and TRPV4-/- isolated bladders. The basal ATP levels were comparable between both groups (Figure 7B). Filling TRPV4 ${ }^{+/+}$bladders to a pressure of $25 \mathrm{mmHg}$ resulted in a substantial release of ATP. However, a significantly smaller ATP release was measured after filling the TRPV4-/- bladders to equal intravesical pressure (Figure 7, B and C; $P<0.05$ ). The infused volume needed to reach a pressure of $25 \mathrm{mmHg}$ was not significantly different between in TRPV4 ${ }^{-/-}(165 \pm 48 \mathrm{ml})$ and $T R P V 4^{+/+}$mice $(145 \pm 25 \mathrm{ml})$.

\section{Discussion}

Here we show several lines of evidence indicating what we believe to be a previously unrecognized role for TRPV4 in normal bladder function. First, we demonstrate that TRPV4 was mainly expressed in bladder basal and intermediate urothelial cells and functioned as a $\mathrm{Ca}^{2+}$ influx pathway activated by hypotonic cell swelling and the specific TRPV4 agonist $4 \alpha$-PDD in these cells. Second, we found that mice lacking TRPV4 displayed a severely disturbed urine-voiding pattern characterized by an increased number of urine spots away from the corners of the cage. Third, cystometric experiments revealed that TRPV4 $4^{-/-}$mice exhibited lower frequency of VCs as well as higher frequency of NVCs. Fourth, we found lower amplitude of SCs in bladders from TRPV4 $4^{-/}$mice. Finally, we observed a decreased stretch-evoked intravesical ATP release in bladders from TRPV4-/- mice.

In $\left[\mathrm{Ca}^{2+}\right]_{i}$ measurements, TRPV4-deficient urothelial cells did not respond to $4 \alpha-P D D$ stimulation and showed a reduced response to cell swelling with respect to cells from $T R P V 4^{+/+}$mice. The residual effect of cell swelling in knockout cells suggests that cell swelling activated $\mathrm{Ca}^{2+}$-permeable channels other than TRPV4. A similar TRPV4-independent response to cell swelling was observed in isolated endothelium cells derived from mouse aorta (17).

$\mathrm{TRPV}^{+/+}$mice exhibited a controlled and organized pattern of voiding, with urine voids occurring almost exclusively in 1 or 2 corners of the housing cage. In TRPV4 $4^{-/}$mice, the main voiding location was also situated at the corners, but the number of urine spots outside of these corners was increased approximately 5-fold. Moreover, the size of the discernible single urine spots was significantly higher in the TRPV4 ${ }^{-/-}$mice, indicating that their bladders filled to a greater extent before voiding was initiated. In agreement herewith, cystometric experiments demonstrated a lower frequency of VCs in TRPV4 $4^{-/}$animals, which was equivalent to longer IVIs and thus larger voiding volumes. These data suggest a significant disturbance in intravesical pressure sensing in the bladders of TRPV4 ${ }^{-/-}$mice.

We observed a higher occurrence of NVCs associated with a lower frequency of VCs. We found no evidence for urine leakage during these NVCs, as this would be expected to produce a higher frequency of small-volume urine spots in the TRPV4 ${ }^{-/}$mice, whereas we mainly observed an increase in high-volume spots. The high occurrence of NVCs could be a compensatory mechanism to increase afferent firing in an attempt to initiate voiding. Other authors have already proposed a similar idea of active contribution of NVCs to afferent signaling $(35,36)$.

Notably, we also observed phenotypic differences in the behavior of isolated bladder strips. In particular, we found that the amplitude of SCs in equally pre-tensed strips was significantly decreased in the TRPV4-/- mice. It is known that stretch increases the amplitude of SCs in normal bladder strips (37). Thus, the lower SC amplitude in the knockout mice is fully in line with a role for TRPV4 in sensing stretch. Removal of the urothelium resulted in decreased SC amplitude in both groups, with no remaining statistical difference between TRPV4 ${ }^{+/+}$and TRPV4 $4^{-/-}$mice. This observation supports an important role for the urothelium in stretchinduced signaling in bladder and indicates that urothelial TRPV4 may be responsible for the observed phenotypic differences in the stretch-evoked behavior of isolated bladder strips. Such a role is consistent with previous studies showing activation of heterologously expressed TRPV4 in response to mechanical stimuli such as cell swelling $(8-11)$ and shear stress $(7,12)$.

It has been reported previously that stretch induces ATP release from both surfaces of isolated uroepithelium (mucosal and serosal), with the largest release at the mucosal side $(38,39)$. The present experiments showed a decreased stretch-evoked intravesical (mucosal) ATP release in decentralized TRPV4-/- bladders. Serosal ATP release from urothelium might also be TRPV4 dependent, but the present data do not allow for conclusions on this point. The 

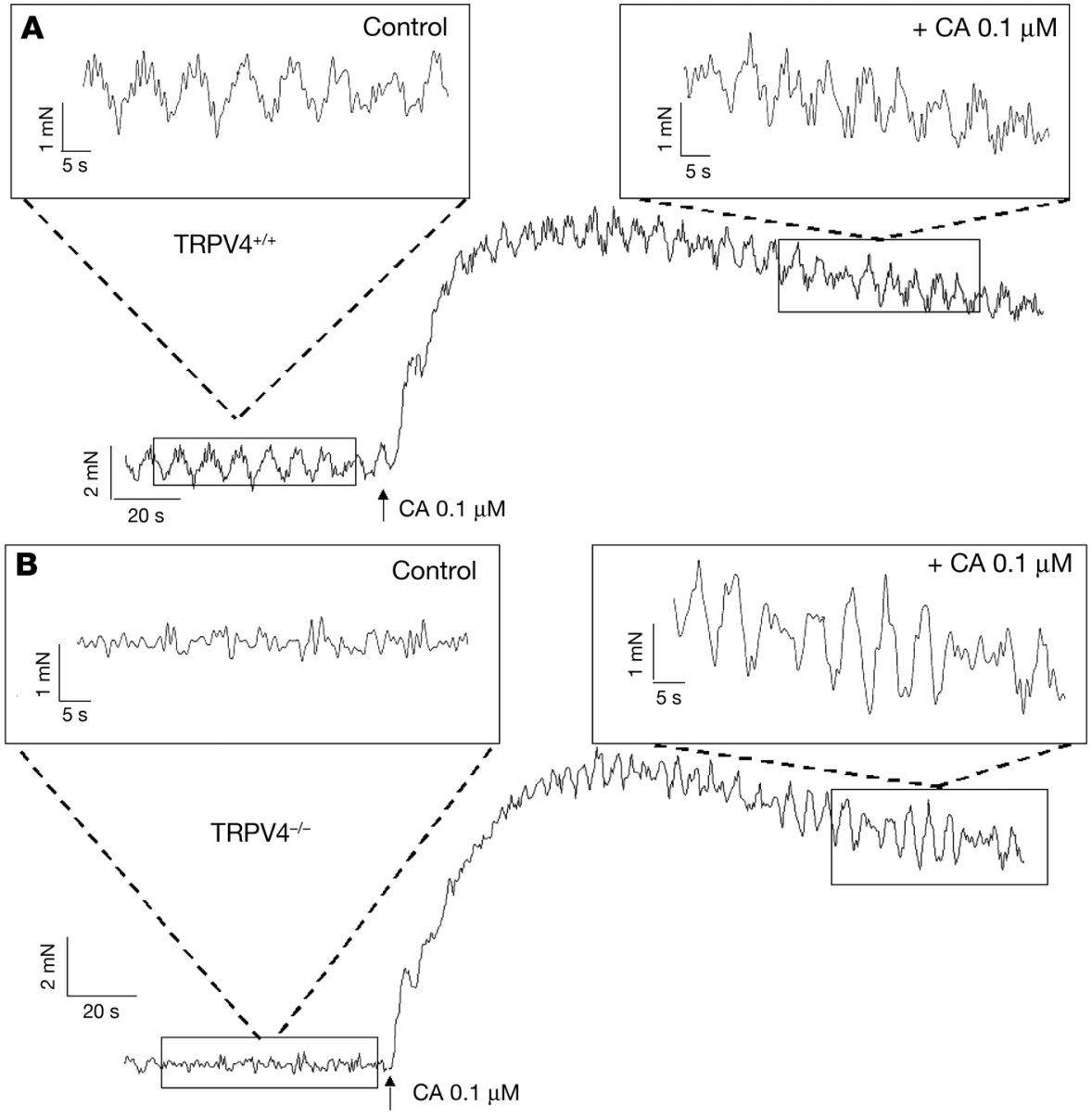

C

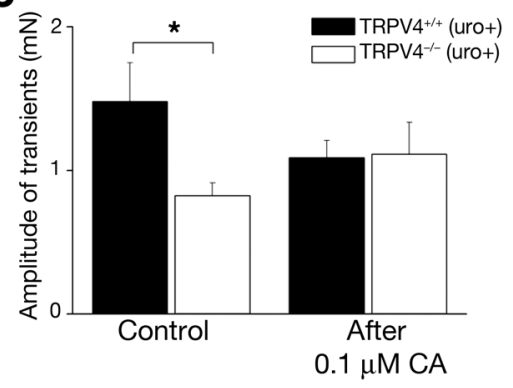

D

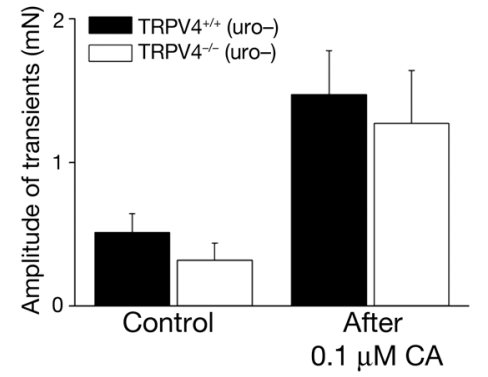

Figure 6

Data from bladder strip experiments. (A and $\mathbf{B})$ Pressure recordings from bladder strips from TRPV4 $4^{+/+}$mice (A) and TRPV4-/mice (B). Control contractility (induced by a constant tension of 1 gram on the bladder strips), followed by carbachol-evoked (CA-evoked) contractile changes. Notice the increase in baseline as main carbachol effect. Insets show more detailed view on spontaneous contractility before (upper left) and after (upper right) administration of carbachol. (C) Different behavior of contractile amplitude before and after carbachol administration in TRPV4 $4^{+/+}$and TRPV4 ${ }^{-1-}$ mice (data are from 6 mice for each group). (D) Removal of urothelium induced an obvious decrease in contractile amplitude in both groups with no remaining significant difference (data are from 6 mice for each group). All data are mean \pm SEM, by unpaired Student's $t$ test. ${ }^{*} P<0.05$.

activation of purinergic receptors localized on umbrella cells. Although speculative, an impairment of such urothelial afferent signaling in TRPV4 $4^{-/}$mice might contribute to a delay in onset of voiding. Future research should clarify if TRPV4 is involved in serosal ATP release from urothelium and if other molecules (such as nitric oxide) are released upon TRPV4 activation. The mechanisms underlying a stretch-induced activation of TRPV 4 are not yet fully elucidated. There is some evidence that cell swelling activates $\mathrm{PLA}_{2}$, which then induces TRPV4 activation through the formation of arachidonic acid and its metabolites $(14,45)$. Thus TRPV4 might be activated by stretch through indirect mechanisms (for a review on the sensory properties of TRP channels, see ref. 3).

It is important to compare our findings with those of Birder and coworkers in TRPV1-/- mice (26). These authors pre-

mechanisms through which TRPV4 activation induces ATP release remain unclear, and several pathways might be involved (39). Intravesically released ATP can exert its effects on the abundant populations of purinergic receptors in (apical) urothelium $\left(\mathrm{P}_{2} \mathrm{X}\right.$ and $\left.\mathrm{P}_{2} \mathrm{Y}\right)(40-42)$, but probably not on purinergic receptors in detrusor (43) or sensory nerve fibers (44), since the urothelium is a highly impermeable epithelial barrier. The mechanisms through which a decreased intravesical ATP release contributes to the observed urodynamic differences can only be speculated on. Wang and coworkers found evidence that serosal but not mucosal release of ATP induces an increase in the apical surface of umbrella cells through $\mathrm{P}_{2} \mathrm{X}$-stimulated membrane insertion (39), which is then probably not a pathway through which intravesical release of ATP exerts its actions. Another possibility is that intravesical release of ATP triggers afferent pathways toward suburothelial nerve fibers through sented strong evidence for a role of TRPV1 in sensation of stretch and pressure in bladder. TRPV1 and TRPV4 are both localized in urothelial cells, with TRPV1 present in all urothelial cell layers (24) and TRPV4 showing a similar urothelial localization, except for its absence on apical membranes of umbrella cells. Thus some partial overlap of the phenotype of the respective knockouts can be expected. Both TRPV1-/- and TRPV4-/- mice show a decreased stretch-evoked ATP release from urothelium. Lack of TRPV1 also leads to an increased frequency of NVCs, but in contrast to our data on the TRPV4-/- mice, no alterations in IVIs were found in TRPV1-/- mice. It thus appears that TRPV4 is necessary for a normal voiding frequency, whereas absence of TRPV1 has no influence on voiding frequency. Moreover, in spotting studies, an increased number of small-diameter urine spots were noticed in TRPV1-/- mice, whereas we found that not only the number of 
A
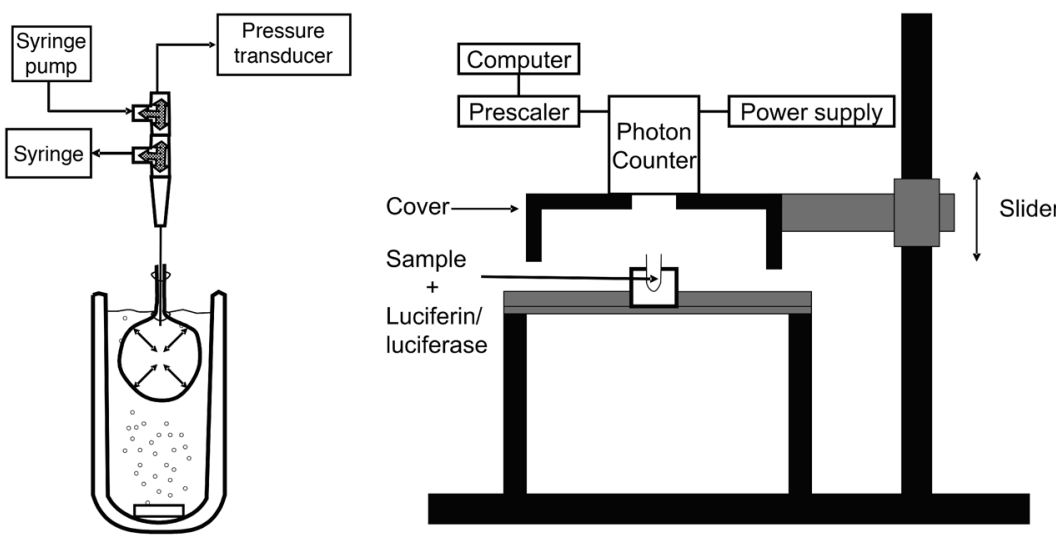

B

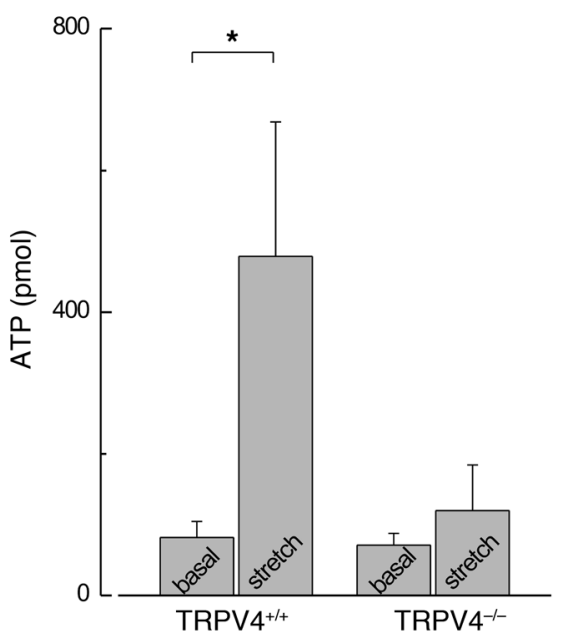

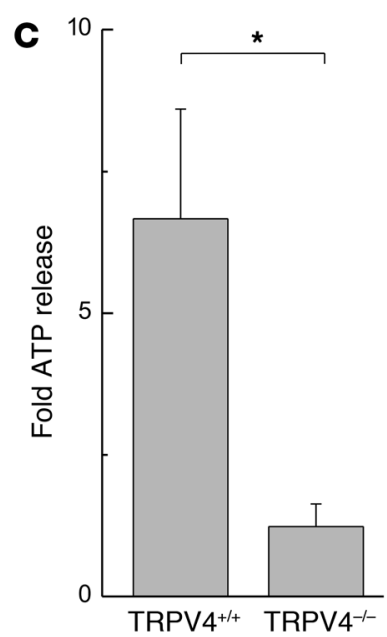

Figure 7

Stretch-induced intravesical ATP release in decentralized bladders from TRPV4+/+ mice and TRPV4 ${ }^{-/-}$mice. (A) Schematic presentation of the in vitro isolated bladder model to measure stretch-evoked ATP release. Left: Isolated bladders were placed in an organ bath and connected via a 3-way tap to a pressure transducer and a syringe pump. Fluid was infused and withdrawn via the 3-way taps. Right: Samples $(50 \mu \mathrm{l})$ were taken from the collected intravesical fluid and $50 \mu \mathrm{l}$ luciferine-luciferase reagent was added to each sample. Bioluminescence was measured using a luminometer. (B) Graph illustrating the absolute amount of intravesical ATP release in isolated bladders in basal conditions and after bladder stretch to $25 \mathrm{mmHg}$. (C) Graph illustrating the fold stretch-evoked intravesical release in ATP compared with baseline values. Data are from 8 animals for each group. All data are mean \pm SEM, by unpaired Student's $t$ test. ${ }^{*} P<0.05$. voiding spots outside the corners of the cage, but also their size, were increased in the TRPV4-/- mice. Unfortunately, to our knowledge, the spatial distribution of urine voiding spots has not been reported for TRPV1/- mice. We hypothesize TRPV4 to be a necessary sensing/transducer molecule for an in-time initiation of the voiding reflex, whereas TRPV1 apparently is involved in different pressure-sensing processes. The differences in bladder phenotype between the 2 knockouts are likely indicative of unique properties of the respective channels.

The urothelium is densely populated with many receptor types and is richly innervated (30), suggesting that it is not only a specialized barrier, but also a tissue for transducing and processing intravesical physical and chemical cues. The urothelial localization of TRPV4 and the observed phenotype in the TRPV4-/- mice strongly suggest a role in sensing and/or transducing intravesical pressure and volume. A deficit in intravesical volume sensing provides a straightforward explanation for the prolonged IVIs together with the numerous large out-of-corner urine spots produced by the TRPV4-/- mice. Clearly, further research is needed to fully establish the role of TRPV4 in stretch sensing in the bladder. Moreover, a contribution of TRPV4 channels in afferent and efferent nerves (19) or in the urethra (46) cannot be fully excluded at this point. Irrespective of the mechanism, our data indicate that TRPV4-/- mice represent a useful new model to study bladder malfunction and suggest that TRPV4 may represent a novel target for the treatment of human bladder disorders.

\section{Methods}

TRPV4 $4^{-/-}$mouse. TRPV4 ${ }^{-/-}$mice and TRPV4 ${ }^{+/+}$littermates backcrossed onto a C57BL/ 6 background (20) were used for these studies. For initial characterization of their urinary tracts, male and female mice (9-12 weeks) were individually housed in metabolic cages and provided diet chow and tap water ad libitum. All experiments were done on mice 9-12 weeks old. All animal experiments were done in accordance to the Katholieke Universiteit Leuven Ethic Regulations and the local animal welfare committees and approved by the animal ethical committee of the Katholieke Universiteit Leuven.

Immunofluorescence. Bladders (from TRPV4 $4^{+/+}$and TRPV4 $4^{-/-}$mice and from rats) were dissected and snap frozen in liquid nitrogen-cooled isopentane. With all antibodies, single and double staining was performed with a sequential fluorescence method on 20- $\mu \mathrm{m}$-thin cryostat sections on 3-aminopropyltriethoxysilane-coated slides. Cryostat sections were dried overnight, fixed in acetone for 10 minutes, and washed in PBS. The sections were subsequently preincubated with a mixture of normal rabbit serum and normal swine serum (diluted 1:5 in PBS) for 30 minutes to block nonspecific epitopes. The slides were incubated with a mixture of polyclonal and monoclonal antibodies at room temperature for $90 \mathrm{~min}$ utes, followed by tetramethylrhodamine isothiocyanate-labeled swine anti-rabbit IgG (TRITC; Dako) and fluorescein isothiocyanate-labeled rabbit anti-mouse IgG (FITC; Dako). The antibodies were diluted in PBS containing $0.3 \%$ Tween 20 (Sigma-Aldrich). The primary polyclonal antibody against TRPV4 was raised against the C-terminal epitope $\left(C^{853} \mathrm{DGHQQG}\right.$ YAPKWRAEDAPL) of rat TRPV4 as described previously in ref. 16 (Supplemental Figure 1). Monoclonal antibodies used were against cytokeratin 7 
(clone OV-TL 12/3; Dako). All incubation steps were followed by a wash in 3 changes of PBS for 5 minutes each. Sections were mounted with glycerol/PBS with para-phenylene-diamine. Controls consisted of omission of the primary antibodies. The slides were examined with an SP5 confocal microscope (Leica Microsystems) equipped with an AOBS, using a HCX PL APO $\times 20.0$ (NA:0.7) dry objective magnification in a sequential scan mode. FITC was monitored with the Ar laser using the 488-nm line for excitation, and emission was detected between 492 and $558 \mathrm{~nm}$. TRITC was excited with the DPSS 561 laser line; emission was detected between 568 and 697 $\mathrm{nm}$. For each fluorophore, the different samples were imaged with equal laser power and equal detector gain.

Immunohistochemistry. Frozen sections ( $4 \mu \mathrm{m}$ thin) were air dried and fixed in acetone before staining with TRPV 4 antibody using the 2-step peroxidase method. Sections were blocked with normal goat serum (dilution 1:5 in PBS) for 7 minutes and an endogenous peroxidase-blocking agent (Dako) for 10 minutes, followed by incubation with the primary antibody for 30 minutes at room temperature. Subsequently slides were incubated with the secondary antibody for 30 minutes at room temperature. The reaction product was developed with 3-amino-9-ethylcarbazole and $\mathrm{H}_{2} \mathrm{O}_{2}(0.01 \%)$, and the sections were counterstained with hematoxylin. Controls consisted of omission of the primary antibody or replacement by normal rabbit immunoglobulins in equivalent amounts. Single immunohistochemical staining was detected using an Axioskop 40 microscope (Carl Zeiss) and recorded and processed with Axiovision software (Carl Zeiss).

Quantitative PCR. Urothelial strips were obtained after incubation of freshly isolated full bladder strips for 1 hour in a "stripper" medium, as described by others (30). Instant quantitative PCR reactions were performed in triplicate using cDNA generated from urothelial cell mRNAs ( $n=4$ per group) and specific mouse TRPV1 and TRPV4 TaqMan assays (Applied Biosystems). Two endogenous controls, GAPDH and $\beta$-actin (Applied Biosystems), were used for normalization. Data (mean \pm SEM) are expressed as fold expression of detected mRNA normalized to TRPV1 mRNA in the TRPV4 $4^{--}$mice, which was used as a calibrator for the comparative analysis.

Culture of urothelial cells. Preparation and characterization of urothelial cultures was done as previously described $(47,48)$. Briefly, TRPV4 $4^{+/+}$and TRPV4 $4^{--}$mice were catheterized and sacrificed. The bladder was rinsed with PBS through the catheter, and the whole bladder was removed aseptically. Urothelial cells were harvested by treatment with trypsin-EDTA $(0.5 \mathrm{~g} / 1$ porcine trypsin and $0.2 \mathrm{~g} / 1 \mathrm{EDTA} / 4 \mathrm{Na}$ in Hank's Balanced Salt Solution with phenol red; Sigma-Aldrich). It was found that 30 minutes of incubation with trypsin-EDTA was efficient in removing all urothelial cells. Afterward, bladders were cut open and the trypsin cell suspension was collected and added to $10 \mathrm{ml}$ of urothelium cell medium (EGM-2; Cambrex). Basal medium was supplemented with and growth factors (hydrocortisone, hEGF, FBS, VEGF, hFGF-B, R3-IGF-1, ascorbic acid, heparin, and gentamicin/amphotericin-B).

After vortexing, the samples were centrifuged and the cell pellet suspended in fresh cell culture medium and seeded on polylysin-coated coverslips. The urothelial origin of the cultured cells was checked with classic immunohistochemistry (cytokeratin 7).

Measurement of $\left[\mathrm{Ca}^{2+}\right]_{i}$ concentrations. For measurement of $\left[\mathrm{Ca}^{2+}\right]_{\mathrm{i}}$ concentrations, the extracellular solution contained (in $\mathrm{mM}$ ): $150 \mathrm{NaCl}, 6 \mathrm{CsCl}$, $1 \mathrm{MgCl}_{2}, 5 \mathrm{CaCl}_{2}, 10$ glucose, and 10 HEPES and was buffered to $\mathrm{pH} 7.4$ with $\mathrm{NaOH}$. When measuring swelling-activated currents, we used an isotonic solution containing (in mM): $105 \mathrm{NaCl}, 6 \mathrm{CsCl}, 5 \mathrm{CaCl}_{2}, 1 \mathrm{MgCl}_{2}, 10$ HEPES, 90 D-Mannitol, 10 glucose, buffered pH 7.4 with $\mathrm{NaOH}(320 \pm 5$ mOsm). Cell swelling was induced by omitting mannitol from this solution (240 mOsm; $25 \%$ reduction of osmolarity). The non-PKC-activating phorbol ester, $4 \alpha-\mathrm{PDD}$ (Sigma-Aldrich), was applied at a $5-\mu \mathrm{M}$ concentra- tion from a $10-\mathrm{mM}$ stock solution in ethanol. $\left[\mathrm{Ca}^{2+}\right]_{\mathrm{i}}$ concentration was measured with a monochromator-based imaging system described in detail previously (45). For every condition, at least 20 cells from at least 3 independent experiments were assayed. The calibration procedure is described in ref. 45. Statistics on $\mathrm{Ca}^{2+}$ increases were done on peak responses.

Analysis of voluntary voiding pattern. Mice were individually placed in $21 \mathrm{~cm}$ $\times 15 \mathrm{~cm}$ cages, and following a 48-hour acclimation period, urine output was collected over 24 hours or in 12-hour light/12-hour dark cycles on sheets of filter paper (Bio-Rad) covering the whole cage area. Collecting papers were photographed with a digital camera under ultraviolet light. Images were scrutinized to identify and analyze the regions corresponding to urine spots using custom-made functions based on the Images toolbox of the software MATLAB (R14). In order to estimate the voiding volume corresponding to individual urine spots, we obtained a linear relationship between this magnitude and the spot area. For this, we determined the correlation between the areas of spots made by known volumes of water. For the filter paper used in actual experiments, $1 \mathrm{~cm}^{2}$ corresponds to $12.5 \mu \mathrm{l}$.

Analysis of locomotor activity and anxiety-like behavior. For open field test (33), mice were placed separately in a corner of a Plexiglas open-field box $(52 \times 52 \times 40 \mathrm{~cm})$ with black vertical walls and a translucent floor dimly illuminated by a lamp placed underneath the box. Activities of each mouse within 5 minutes in the open field were automatically recorded by an EthoVision image motion system (Noldus Information Technology Inc.). The floor of the open field was divided by software programming into center, periphery, and corner zones, defined by $2 \times 2$ parallel lines spaced $10 \mathrm{~cm}$ from the side walls. The behavioral parameters calculated using Ethovision Software during 5-minute sessions were total distance traveled, velocity, time spent in the different zones (center, corners, and periphery), and distance traveled in the zones.

The light/dark exploration test (34) was performed by placing the mouse in a cage $(52 \times 52 \times 40 \mathrm{~cm})$ divided into 2 compartments, 1 brightly lit from above and 1 dark. The mouse was initially placed in the dark compartment, and the time spent in and the number of transitions between the compartments were recorded for 5 minutes.

Cystometric experiments. Polyethylene catheters (Becton Dickinson) were implanted intravesically in generally anesthetized male mice (TRPV4+/+ and TRPV4-/-). Vision was optimized by the use of a surgical microscope (Carl Zeiss). Anesthesia was performed by intraperitoneal injections of ketamine/domitor $(0.08 \mathrm{ml} / 10 \mathrm{~g}$ body weight of mixture $15 \mathrm{ml}$ ketamine, $0.2 \mathrm{ml}$ domitor, and $1.65 \mathrm{ml}$ saline; CEVA). Recovery was facilitated with intraperitoneal antisedan $(0.1 \mathrm{ml} / 100 \mathrm{~g}$ body weight of mixture $1 \mathrm{ml}$ antisedan and $4 \mathrm{ml}$ saline; CEVA). A minilaparotomy was made, the bladder was exteriorized, and a circumferential suture with a fine silk ligature was made at the bladder fundus. The bladder was opened in the center of the suture, the polyethylene catheter was inserted, and the suture was closed. A cuff was made at the end of each catheter to consolidate its intravesical location. If leakage was absent, the catheter was tunnelled subcutaneously to the interscapular region and sutured to the skin. The laparotomy was closed in layers. Amoxicillin was given subcutaneously $(0.1 \mathrm{cc})$. Three days after surgery mice were habituated to a restraining cage, and on the fourth day, cystometric experiments were performed. Mice were placed in the restraining cage; the catheter was flushed with saline to check its permeability, and was then connected by an appropriate adapter (Becton Dickinson) to a 3-way tab, with the fluid-filled pressure line at one end, and injectionpumps (Harvard Apparatus) to the other. Pressure lines were connected to a DTX plus disposable pressure transducer (Becton Dickinson; zero offset, $25 \mathrm{mmHg}$; natural frequency, $100 \mathrm{~Hz}$ ), from which the output was amplified and recorded using the Windaq system (Dataq Instruments). Pressure transducers were calibrated before every experiment. Bladders were filled at constant rate $(20 \mu \mathrm{l} / \mathrm{min}$ ) with Krebs solution (in mM: $118 \mathrm{NaCl}, 4.6 \mathrm{KCl}$, 
2.5 $\mathrm{CaCl}_{2}, 1.2 \mathrm{MgSO}_{4}, 1.2 \mathrm{KH}_{2} \mathrm{PO}$, and $25 \mathrm{NaHCO}_{3}, 11$ glucose; buffered at $\mathrm{pH} 7.4,320 \pm 5 \mathrm{mOsm})$. Urine was collected with absorptive paper to estimate the total amount of urine per void. Data from cystometric experiments were analyzed by calculating the frequency, amplitude, and duration of voiding and NVCs (during filling phase). Voiding duration was defined as the period between the start of voiding and the point at which postvoiding pressure had decreased to $25 \%$ of total voiding pressure; IVI was defined as the period between the end of voiding and the start of a new voiding episode. NVCs were defined as minimal amplitude of $1 \mathrm{~cm} \mathrm{H}_{2} \mathrm{O}$ and a minimal duration of 3 seconds.

Muscle strip experiments. Bladders were dissected, placed in freshly made Krebs solution (for content, see Cystometric experiments) and cut longitudinally from the base toward the fundus on 2 sides, to yield one longitudinal strip. Bladder strips denuded from urothelium were obtained by gently scraping off the urothelium with a sharp scalpel blade. Histological absence of urothelium confirmed the validity of this technique. Each strip was placed in an organ bath filled with freshly made Krebs solution and attached with a fine ligature to a steel hook on one side and to a fixed force transducer on the other side (Harvard Apparatus). The bathing solution was constantly gassed with a mixture of oxygen $(95 \%)$ and $\mathrm{CO}_{2}(5 \%)$, and the temperature was maintained between $35^{\circ} \mathrm{C}$ and $37^{\circ} \mathrm{C}$ with a controlled $\mathrm{pH}$ of 7.4. Transducers were calibrated before each experiment. Pre-tension was exerted using a 1-gram weight. Bladder strips were allowed to stabilize their contractile activity for 30 minutes before the experiment started. Subsequently the effects of carbachol $(0.1 \mu \mathrm{M})$ on spontaneous contractility were tested. Carbachol (Sigma-Aldrich) was dissolved in purified water and stored at $4^{\circ} \mathrm{C}$. Tension was digitally recorded with custom-made software and analyzed offline with OriginPro 6.1 software (OriginLab Corp.). Tension signals were analyzed by defining minimal amplitude of $0.5 \mathrm{mN}$ and a minimal duration of 3 seconds for contractions.

ATP measurement. Bladders were dissected, and a small catheter (22 Gauche, Insyste-W; Becton Dickinson) was inserted through the urethra and successively fixed with a $6 / 0$ silk ligature. The ureters were ligated. The system was checked for leakage by filling and emptying the bladder before placing it in the organ bath. Subsequently the bladder was placed in an organ bath filled with freshly made Krebs solution (for content, see cystometric experiments). The bathing solution was constantly gassed with a mixture of oxygen $(95 \%)$ and $\mathrm{CO}_{2}(5 \%)$, and the temperature was maintained between $35^{\circ} \mathrm{C}$ and $37^{\circ} \mathrm{C}$, with a controlled $\mathrm{pH}$ of 7.4 . The catheter was attached to a 3-way tap that in turn was connected to a volume pump (Harvard apparatus) and a DTX plus pressure transducer (Becton Dickinson), the output of which was amplified and recorded using the Windaq system (Dataq Instruments).

To obtain baseline ATP samples, bladders were filled with $50 \mu$ l of Krebs (30 seconds at an infusion rate of $100 \mu \mathrm{l} / \mathrm{min}$ ) and left to equilibrate for 30 minutes. Then bladders were emptied via the 3 -way tab, and $50-\mu 1$ samples were taken for analysis. After 3 to 4 equilibration cycles, bladders were filled with $50 \mu \mathrm{l}$, left to equilibrate for 30 minutes, and then filled at constant

1. Clapham, D.E., Montell, C., Schultz, G., and Julius, D. 2003. International Union of Pharmacology. XLIII. Compendium of voltage-gated ion channels: transient receptor potential channels. Pharmacol. Rev. 55:591-596.

2. Vriens, J., et al. 2004. Invertebrate TRP proteins as functional models for mammalian channels. Pflugers Arch. 449:213-226.

3. Voets, T., Talavera, K., Owsianik, G., and Nilius, B. 2005. Sensing with TRP channels. Nat. Chem. Biol. 1:85-92.

4. Nilius, B., Owsianik, G., Voets, T., and Peters, J.A. 2007. Transient receptor potential channels in disease. Physiol. Rev. 87:165-217.

5. Watanabe, H., et al. 2002. Activation of TRPV4 channels (hVRL-2/mTRP12) by phorbol derivatives. J. Biol. Chem. 277:13569-13577.

6. Nilius, B., Droogmans, G., and Wondergem, R. 2003. Transient receptor potential channels in endothelium: solving the calcium entry puzzle? Endothelium. 10:5-15.

7. Kohler, R., et al. 2006. Evidence for a functional role of endothelial transient receptor potential V4 in shear stress-induced vasodilatation. Arterioscler. Thromb. Vasc. Biol. 26:1495-1502.

8. Wissenbach, U., Bodding, M., Freichel, M., and Flockerzi, V. 2000. Trp12, a novel Trp related protein from kidney. FEBS Lett. 485:127-134.

9. Strotmann, R., Harteneck, C., Nunnenmacher, K., Schultz, G., and Plant, T.D. 2000. OTRPC4, a non- speed $(100 \mu \mathrm{l} / \mathrm{min})$ to a pressure of $25 \mathrm{mmHg}$ to obtain stretch-evoked AT samples. Once the pressure was reached, the bladder was emptied and rations of ATP. The sample was inserted in a light-tight chamber, and the ATP-dependent chemiluminescence was captured by an H3460 head-on Instruments) hosted in a generic desktop PC. Software was developed by A. egal under NI LabWindows/CVI (National Instruments) to program the t on disc for subsequent analysis.

Statistics. Significance between individual groups was tested using Acknowledgments

P. de Witte (Labo Farmaceutische Biologie, Katholieke thiverite Leuven [KU Leuven], Leuven, Belgium) for his assisof the TRP channel group at KU Leuven for critical discussion. Van Lommel, P. Aertsen, and M. Verhoeven (all at the Division J. Vriens, I. Dewachter, and D. Daelemans are postdoctoral fellows of the Fonds voor Wetenschappelijk Onderzoek, Flanders (FWO). . Everaerts is a doctoral fellow of the FWO. This work was supgerian Federal Government, the Flem2004/07, FWO G.0136.00, and FWO G.0172.03 and funding from Interuniversity Poles of Attraction Program, the Prime Min(to D. Daelemans), Wetenschappelijk Onderzoek Multiple Sclerose (to D. De Ridder) and Charcot Foundation (to D. De Ridder).

Received for publication February 9, 2007, and accepted in revised Address correspondence to: Bernd Nilius, KU Leuven, Department (olecular Cell Biology, Division of Physiology, Laboratory of (3) Campus Gasthuisberg, Herestraat 49, Bus 802, B-3000 Leuven, Belgium. Phone: 0032-16-345-937; Fax: 0032 16-345-991; E-mail: bernd.nilius@med.kuleuven.be.

\section{Thomas Gevaert and Joris Vriens are co-first authors.}

selective cation channel that confers sensitivity to extracellular osmolarity. Nat. Cell Biol. 2:695-702.

10. Liedtke, W., et al. 2000. Vanilloid receptor-related osmotically activated channel (VR-OAC), a candidate vertebrate osmoreceptor. Cell. 103:525-535.

11. Nilius, B., Prenen, J., Wissenbach, U., Bodding, M., and Droogmans, G. 2001. Differential activation of the volume-sensitive cation channel TRP12 (OTRPC4) and volume-regulated anion currents in HEK-293 cells. Pflugers Arch. 443:227-233.

12. Gao, X., Wu, L., and O'Neil, R.G. 2003. Temperature-modulated diversity of TRPV4 channel gating: activation by physical stresses and phorbol ester derivatives through protein kinase C-dependent and -independent pathways. J. Biol. Chem. 
278:27129-27137.

13. Smith, P.L., Maloney, K.N., Pothen, R.G., Clardy, J., and Clapham, D.E. 2006. Bisandrographolide from Andrographis Paniculata activates TRPV4 channels. J. Biol. Chem. 281:29897-29904.

14. Watanabe, H., et al. 2003. Anandamide and arachidonic acid use epoxyeicosatrienoic acids to activate TRPV4 channels. Nature. 424:434-438.

15. Vriens, J., et al. 2005. Modulation of the Ca2 permeable cation channel TRPV4 by cytochrome P450 epoxygenases in vascular endothelium. Circ. Res. 97:908-915.

16. Guler, A.D., et al. 2002. Heat-evoked activation of the ion channel, TRPV4. J. Neurosci. 22:6408-6414.

17. Watanabe, H., et al. 2002. Heat-evoked activation of TRPV4 channels in a HEK293 cell expression system and in native mouse aorta endothelial cells. J. Biol. Chem. 277:47044-47051.

18. Nilius, B., Vriens, J., Prenen, J., Droogmans, G., and Voets, T. 2004. TRPV4 calcium entry channel: a paradigm for gating diversity. Am. J. Physiol. Cell Physiol. 286:C195-C205

19. Suzuki, M., Mizuno, A., Kodaira, K., and Imai, M. 2003. Impaired pressure sensation in mice lacking TRPV4. J. Biol. Chem. 278:22664-22668.

20. Liedtke, W., and Friedman, J.M. 2003. Abnormal osmotic regulation in trpv $4^{-/}$mice. Proc. Natl. Acad. Sci.U.S. A. 100:13698-13703.

21. Mizuno, A., Matsumoto, N., Imai, M., and Suzuki, M. 2003. Impaired osmotic sensation in mice lacking TRPV4. Am. J. Physiol. Cell Physiol 285:C96-C101.

22. Todaka, H., Taniguchi, J., Satoh, J., Mizuno, A., and Suzuki, M. 2004. Warm temperature-sensitive transient receptor potential vanilloid 4 (TRPV4) plays an essential role in thermal hyperalgesia. J. Biol. Chem. 279:35133-35138.

23. Lee, H., Iida, T., Mizuno, A., Suzuki, M., and Caterina, M.J. 2005. Altered thermal selection behavior in mice lacking transient receptor potential vanilloid 4 J. Neurosci. 25:1304-1310.

24. Birder, L.A., et al. 2001. Vanilloid receptor expression suggests a sensory role for urinary bladder epithelial cells. Proc. Natl. Acad. Sci. U. S. A. 98:13396-13401.
25. Ost, D., Roskams, T., Van Der Aa, F., and De Ridder, D. 2002. Topography of the vanilloid receptor in the human bladder: more than just the nerve fibers. J. Urol. 168:293-297.

26. Birder, L.A., et al. 2002. Altered urinary bladder function in mice lacking the vanilloid receptor TRPV1. Nat. Neurosci. 5:856-860.

27. Andrade, E.L., Ferreira, J., Andre, E., and Calixto, J.B. 2006. Contractile mechanisms coupled to TRPA1 receptor activation in rat urinary bladder. Biochem. Pharmacol. 72:104-114.

28. Tsukimi, Y., Mizuyachi, K., Yamasaki, T., Niki, T. and Hayashi, F. 2005. Cold response of the bladder in guinea pig: involvement of transient receptor potential channel, TRPM8. Urology. 65:406-410.

29. Mukerji, G., et al. 2006. Cool and menthol receptor TRPM8 in human urinary bladder disorders and clinical correlations. BMC Urol. 6:6.

30. Birder, L.A. 2005. More than just a barrier: urothelium as a drug target for urinary bladder pain. $A m$. J. Physiol. Renal Physiol 289:F489-F495.

31. Erman, A., Veranic, P., Psenicnik, M., and Jezernik, K. 2006. Superficial cell differentiation during embryonic and postnatal development of mouse urothelium. Tissue Cell. 38:293-301.

32. Romih, R., Jezernik, K., and Masera, A. 1998. Uroplakins and cytokeratins in the regenerating rat urothelium after sodium saccharin treatment. Histochem. Cell Biol. 109:263-269.

33. Salas, R., Pieri, F., Fung, B., Dani, J.A., and De Biasi, M. 2003. Altered anxiety-related responses in mutant mice lacking the beta 4 subunit of the nicotinic receptor. J. Neurosci. 23:6255-6263.

34. Crawley, J., and Goodwin, F.K. 1980. Preliminary report of a simple animal behavior model for the anxiolytic effects of benzodiazepines. Pharmacol. Biochem. Behav. 13:167-170

35. Coolsaet, B.L., Van Duyl, W.A., Van Os-Bossagh, P., and De Bakker, H.V. 1993. New concepts in relation to urge and detrusor activity. Neurourol. Urodyn. 12:463-471.

36. Gillespie, J.I. 2004. The autonomous bladder: view of the origin of bladder overactivity and sensory urge. BJU Int. 93:478-483.

37. Finkbeiner, A.E. 1999. In vitro responses of detru- sor smooth muscle to stretch and relaxation. Scand. J. Urol. Nephrol. Suppl. 201:5-11.

38. Knight, G.E., Bodin, P., De Groat, W.C., and Burnstock, G. 2002. ATP is released from guinea pig ureter epithelium on distension. Am. J. Physiol. Renal Physiol. 282:F281-F288.

39. Wang, E.C., et al. 2005. ATP and purinergic receptor-dependent membrane traffic in bladder umbrella cells. J. Clin. Invest. 115:2412-2422. doi:10.1172/ JCI24086.

40. Elneil, S., Skepper, J.N., Kidd, E.J., Williamson, J.G., and Ferguson, D.R. 2001. Distribution of P2X(1) and $\mathrm{P} 2 \mathrm{X}(3)$ receptors in the rat and human urinary bladder. Pharmacology. 63:120-128.

41. Lee, H.Y., Bardini, M., and Burnstock, G. 2000. Distribution of $\mathrm{P} 2 \mathrm{X}$ receptors in the urinary bladder and the ureter of the rat. J. Urol. 163:2002-2007.

42. Birder, L.A., et al. 2004. Alterations in P2X and P2Y purinergic receptor expression in urinary bladder from normal cats and cats with interstitial cystitis. Am. J. Physiol. Renal Physiol. 287:F1084-F1091.

43. O'Reilly, B.A., et al. 2002. P2X receptors and their role in female idiopathic detrusor instability. J. Urol. 167:157-164.

44. Ruan, H.Z., et al. 2006. Expression of P2X and P2Y receptors in the intramural parasympathetic ganglia of the cat urinary bladder. Am. J. Physiol. Renal Physiol. 290:F1143-F1152.

45. Vriens, J., et al. 2004. Cell swelling, heat, and chemical agonists use distinct pathways for the activation of the cation channel TRPV4. Proc. Natl. Acad. Sci. U. S. A. 101:396-401.

46. Combrisson, H., Allix, S., and Robain, G. 2007. Influence of temperature on urethra to bladder micturition reflex in the awake ewe. Neurourol. Urodyn. 26:290-295.

47. Southgate, J., Masters, J.R.W., and Trejdosiewicz, L.K. 2002. Culture of human urothelium. In Culture of epithelial cells (Culture of specialized cells). I. Freshney and M.G. Freshney, editors. Wiley-Liss, Inc. New York, New York, USA. 381-389.

48. Huygens, A., et al. 2005. Permeation of hypericin in spheroids composed of different grade transitional cell carcinoma cell lines and normal human urothelial cells. J. Urol. 174:69-72. 